\title{
Linha de Montagem para a Produção de Habitações de Interesse Social Modular em Light Steel Frame
}

\author{
André Luiz Vivan \\ José Carlos Paliari
}

\section{Introdução}

Tradicionalmente, o processo de produção de edificações é caracterizado pela movimentação dos operários, máquinas (se necessário) e materiais em áreas que circundam o espaço ocupado pelo produto que está sendo construído, ou seja, o produto é fixo enquanto operários e máquinas movimentam-se em praticamente todo o recinto que forma o canteiro de obras. Além disso, grande parte das empresas construtoras procuram melhorias nas atividades de processamento, tornando-as mais eficientes em vez de torná-las mais eficazes (KOSKELA, 1992). Assim, entende-se que a mudança nas bases técnicas seja indispensável para a aplicação de inovações que rompam com o que tradicionalmente é praticado. Tal ação pode ser justificada pelo fato de que as práticas tradicionais na construção estão se tornando cada vez mais inadequadas, tendo em vista o crescimento contínuo da complexidade dos empreendimentos e da necessidade de rapidez de entrega dessas edificações (KOSKELA, 2000; KOSKELA; VRIJHOEF, 2001; KOSKELA, 2004; BERTELSEN et al.,2008).

Nesse sentido, mudanças nas bases técnicas de produção são uma das transformações mais fundamentais que podem ser introduzidas na indústria da construção. O uso de novos sistemas de produção, como os denominados flow shop, 
mostram-se adequados nesse contexto, em que as linhas de montagem são uma das técnicas que melhor definem tais métodos. De acordo com Gomes (2002), o termo flow shop representa os sistemas de produção projetados a fim de fazer com que os processos e os equipamentos necessários às tarefas estejam organizados conforme as etapas sequenciais de produção pelas quais o produto é fabricado. Bachega (2013) acrescenta ainda que os ambientes flow shop atuam, basicamente, em um fluxo de peças/materiais e os equipamentos são de uso dedicado e específico.

Tubino (1999) indica algumas vantagens do uso de ambientes flow shop, como o controle simplificado da produção, a facilidade em otimizar o sistema, a redução do lead time da produção, entre outras. Assim, considerando a produção de habitações em um ambiente flow shop, recorreu-se às linhas de montagem como método de produção. Na visão de Bautista e Pereira (2007), uma linha de montagem é formada por um determinado número de estações de trabalho, que são dispostas em série ou em paralelo, nas quais os serviços se desenvolvem por meio de um fluxo de produção. Os autores afirmam que tais estações são integradas por um sistema de transporte, cujo objetivo é suprir o elemento (ou produto a ser fabricado) de componentes e movimentar a produção de uma estação de trabalho a outra.

Tendo em vista o breve contexto apresentado, é necessário indicar a tecnologia mais adequada a uma perfeita combinação entre o produto e o sistema de produção. Dessa forma, foi selecionado o sistema construtivo Light Steel Frame (LSF), pois, simplificadamente, o LSF pode ser definido como um sistema formado por estrutura composta a partir da associação de elementos fabricados em perfis de aço conformados a frio, que constituem os elementos estruturais e associam-se a diversos outros sistemas, como o de vedação, o qual, geralmente, utiliza placas pré-fabricadas com capacidade de variar sua composição. Mas a principal vantagem do LSF pode ser identificada nos atributos dos seus elementos, que caracterizam a produção de edificações em LSF como essencialmente de montagem, fato que representa uma grande vantagem sobre sistemas construtivos baseados na alvenaria, por exemplo.

Dessa maneira, a justificativa do uso do LSF baseia-se em suas características de industrialização, inerentes aos seus processos e subprocessos, em relação às características de trabalho em uma linha de montagem que exige a pré-fabricação. Além disso, o LSF, como qualquer estrutura metálica, possui outro atributo representado pela precisão dimensional, de ordem de grandeza milimétrica de seus componentes, em função das características do aço e dos processos de fabricação dos componentes. Essa precisão pode ser mais difícil de ser obtida com outros materiais de uso comum na construção, como a madeira para o sistema Wood Frame.

Considerando a indústria da construção, o uso de um sistema produtivo definido por linha de montagem é algo pouco explorado, tanto no âmbito acadêmico quanto comercial. Assim, a adoção de linhas na indústria da construção implica que as casas, 
como produtos finais, sejam produzidas dentro de uma fábrica. Conforme afirmação de Lee e Englin (1989), casas manufaturadas são inteiramente produzidas em uma fábrica e, assim, oferecem uma grande vantagem econômica sobre casas construídas de maneira convencional. Em termos operacionais, o processo de produção de habitações industrializadas consiste em várias atividades realizadas em uma linha de montagem, que deverão ser muito bem planejadas para garantir uma construção contínua (sem imprevistos) (MEHROTRA; SYAL; HASTAK, 2003).

Assim, de acordo com o conteúdo exposto, foi proposto o desenvolvimento de um sistema de produção flow shop, utilizando linhas de montagem manuais como técnica de produção para unidades habitacionais modulares em LSF. O sistema desenvolvido foi modelado e simulado computacionalmente, no intuito de avaliar o seu comportamento, basicamente, em termos de rapidez de entrega das unidades habitacionais e redução de desperdícios.

\section{Metodologia}

O projeto de uma linha de montagem envolve a integração entre o projeto dos produtos, processos e o layout da fábrica, uma vez que os produtos devem ser desenvolvidos com base nas regras de projetos para produção e nas restrições produtivas entre tarefas (REKIEK; DELCHAMBRE, 2006). A fabricação de um item na linha de montagem é dividida em um conjunto de tarefas conhecidas, e, para cada estação de trabalho, é atribuído um subconjunto de tarefas denominadas "cargas de trabalho da estação", as quais são únicas e específicas para cada estação. Cada tarefa demanda um tempo de operação, que deve ser determinado em função das tecnologias de fabricação utilizadas e os recursos (máquinas, ferramentas, etc.) empregados (BAUTISTA; PEREIRA, 2007).

Assim, uma casa manufaturada é produzida em um ambiente controlado de uma fábrica e, uma vez concluída, é transportada para o destino final no qual será instalada e conectada com as demais instalações, como fundações e sistemas prediais (MEHROTRA; SYAL; HASTAK, 2005). Os autores mostram que, para a montagem da unidade habitacional, são necessárias várias estações de trabalho de diferentes tipos, as quais podem estar agrupadas em linhas principais, células de produção ou em linhas alimentadoras. Além disso, as estações de trabalho devem ser adequadas para comportar as ferramentas e máquinas necessárias para o desenvolvimento das atividades atribuídas. Após a realização de diversos estudos de caso em várias indústrias do ramo, Hammad (2002) e Mehrotra; Syal e Hastak (2005) sugerem uma divisão das tarefas de montagem de uma casa para uso em linhas de montagem, independente da tecnologia de construção, que serviu de base para o desenvolvimento do sistema proposto neste estudo. 
Com as devidas adaptações na proposta dos autores, portanto, foi desenvolvido o sistema de produção deste trabalho, bem como o seu respectivo modelo computacional, adequadamente validado para posterior simulação computacional. O modelo computacional foi elaborado no ambiente do software ProModel ${ }^{\circledR}$, desenvolvido pela ProModel Corporation $^{\circledR}$, obedecendo todas as premissas de programação do software para o correto funcionamento do modelo. No que tange à programação, destaca-se a lógica de cada estação de trabalho, que foi estruturada com a regra FIFO (First In First Out), como condição para recebimento e liberação dos elementos a serem processados ou já processados. Com relação aos recursos de transporte, estes foram definidos por plataformas de montagem. Tais recursos de transporte possuem atributos como velocidade, ponto de partida, aceleração, entre outros, que foram informados ao software e sofreram alterações ou não, dependendo das condições de simulação. Outros atributos como equipes e suas características e máquinas, como pontes rolante, também foram inseridos no modelo.

Por último, a construção do modelo também contempla as definições a respeito dos produtos. Além dos tempos de processamento que são característicos das tarefas de montagem, o software necessita que sejam informadas as quantidades de produção e as frequências de entrega de cada elemento. Assim, para o modelo, foram consideradas variações nos processos. Dessa forma, as porcentagens de variação foram obtidas considerando que, segundo Lane (2007), em sistemas de baixo volume de produção, é usual que os tempos variem em um intervalo máximo de menos 15\% e mais $15 \%$. O autor considera que essa variação é aceitável e, normalmente, o sistema a compensa naturalmente ao longo dos postos de trabalho.

Com essa variação, os tempos das estações de trabalho descritos nos resultados são entendidos como tempos padrão de processamento das atividades, possuindo limites inferior e superior definidos com base na variação descrita, de maneira que o lead time associado à tarefa de cada operário nos postos de trabalho variou dentro de tais limites. A variabilidade de processos atribuída ao modelo configura o caráter estocástico de suas simulações computacionais. Além disso, sendo um modelo estocástico, entende-se que o seu comportamento seja algo mais próximo do que seria observado em um sistema de produção real, dado que, por ser composto de linhas manuais, a variabilidade de processo é algo mais recorrente, mas com capacidade de ser melhor controlada por ser um ambiente de fábrica. A seguir, são apresentadas as informações relativas à lógica do modelo, principalmente com relação às variáveis incorporadas nele.

Além da programação básica que representa a sequência e o processamento das atividades de cada estação de trabalho, o modelo também foi alimentado com variáveis que foram utilizadas como parâmetros e medidas para comparação entre cenários. Como explicitado, todo o transporte dos módulos ao longo das linhas é feito 
pelas plataformas. Assim, houve a necessidade de não somente declarar e atribuir as plataformas como recursos de transporte, mas também determinar qual o melhor número desse recurso nas linhas e suas respectivas velocidades. Tais atributos das plataformas são classificados como variáveis independentes do modelo, no qual também se introduziu o WIP como variável independente. As variáveis dependentes no modelo são: Tempo de ciclo (C); Lead time; Tempos de espera e bloqueio; Eficiência do sistema (E).

Ainda dentro do contexto de lógica de funcionamento do modelo, destaca-se que ele foi programado a partir das premissas do Just-in-Time (JIT), com a associação do Kanban na programação das ordens de produção. Assim, algumas das variáveis anteriormente enumeradas também foram utilizadas para a programação do sistema JIT nos modelos. Junto a tais variáveis, também foram criados atributos, que são específicos da programação e assumem valores absolutos para cada cenário, necessários para o cálculo das variáveis dependentes. O cálculo dos tempos de ciclo, tempos de produção, WIP, etc. foi feito a partir da inserção dessas variáveis em determinadas linhas de comando do modelo, em associação com alguns comandos reservados ao ProModel $^{\circledR}$.

\section{Resultados}

\subsection{Unidade Habitacional em Light Steel Frame}

Foi projetada uma unidade habitacional composta pela união de quatro módulos de dimensões iguais, de acordo com as restrições técnicas e tecnológicas do sistema LSF. Com relação aos módulos, cada um possui dimensões que foram restringidas por dois fatores principais: transporte rodoviário e placas de vedação. Assim, para condições usuais de transporte rodoviário, uma das dimensões do módulo possui 2,60 m (largura) entre montantes externos, excluindo-se, portanto, as placas de vedações externas, acabamento e beiral. A segunda dimensão, embora mais livre, foi estabelecida em função da largura das placas de vedação (e suas juntas). Dessa forma, decidiu-se pelo uso de três placas e suas respectivas juntas, o que resultou em um comprimento de 3,59 m. Na Figura 1, pode ser analisada a planta da unidade habitacional.

Cada módulo possui uma estrutura independente, o que garante a sustentação de sua respectiva laje e cobertura sem a necessidade de estruturas especiais ou provisórias, de maneira que, uma vez concluídos, são apenas acoplados uns aos outros de acordo com o layout da arquitetura. A seguir, são apresentados alguns atributos mais específicos das unidades habitacionais e seus elementos.

A unidade projetada consiste em cinco cômodos divididos em quatro módulos de 9,42 m2 cada um, totalizando 37,66 $\mathrm{m}^{2}$ com o acabamento. O pé-direito de cada 
módulo alcança os 2,50 m, também considerando o acabamento no piso e laje. 0 beiral da casa possui 0,30 m e avança por todos os lados da edificação.

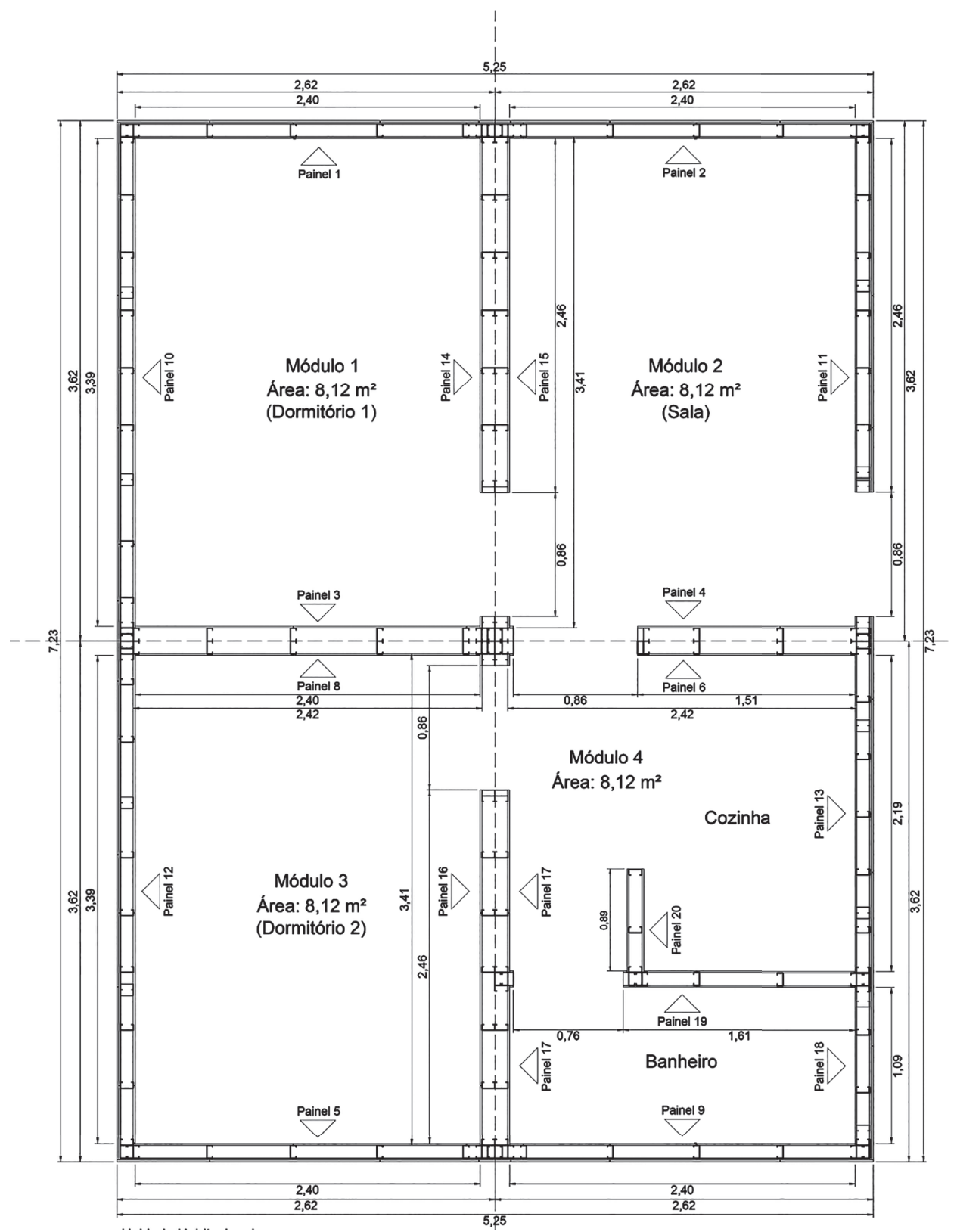

Figura 1 - Planta da unidade habitacional composta por quatro módulos. 
Com relação aos cômodos, os Módulos 1 e 3 representam os dois dormitórios da unidade. O Módulo 2 é destinado à sala de estar, comportando também a entrada da unidade. No Módulo 4, encontram-se um corredor de acesso, a cozinha e o banheiro, que contabilizam 1,93 $\mathrm{m}^{2}, 3,40 \mathrm{~m}^{2}$ e 2,52 $\mathrm{m}^{2}$ respectivamente. No que diz respeito à montagem final da unidade (acoplamento dos módulos), ela só é realizada quando os quatro módulos encontram-se em seu destino, que deve estar com as fundações concluídas.

A montagem de todos os elementos dos módulos obedece rigorosamente às características do LSF como sistema construtivo, tanto em termos de sequência de montagem quanto em termos de desempenho. Para melhor se adequar às características do sistema de produção, foi considerado o uso de kits (montados em células de produção) para instalações prediais, a exemplo do uso do PEX para instalações hidráulicas). Para os módulos 1, 2 e 3, o acabamento dos painéis é representado pelo uso de papel de parede previamente cortado, e o acabamento dos pisos é feito com laminado de madeira, cujas peças também são previamente cortadas. 0 módulo 4, por apresentar áreas molháveis, é revestido (nestas áreas) por vinil nas paredes e pisos. Externamente, todos os módulos são revestidos com siding vinílico fixado sobre a manta hidrofugante. As portas e janelas constituem kits e são fixadas com espuma de poliuretano nas aberturas correspondentes. Finalmente, a fixação de mata-juntas, rodapés e demais atividades de acabamento são executadas ainda com os módulos separados, restando as juntas externas e internas, oriundas do acoplamento entre os módulos, as quais são devidamente tratadas após a instalação final.

\subsection{O Sistema de Produção Proposto}

O sistema de produção é composto por uma linha de montagem principal em formato $U$, além de outras três linhas alimentadoras e células de produção. A linha principal, denominada Linha Alfa, foi concebida em formato $U$, com uma extensão linear de 385 m, composta por 15 estações de trabalho e 2 pontos de inspeção. Tal linha recebe elementos do LSF de 3 linhas alimentadoras: Linhas Beta e Gama, com 22 m, e linha Delta, com 62 m. As linhas alimentadoras são estruturadas por três estações de trabalho cada uma, com exceção da Linha Delta, que possui quatro estações. A estrutura destinada a receber as atividades de montagem é chamada de plataforma, a qual é transportada ao longo do tajeto por trilhos que seguem o curso das linhas. Por fim, há 10 células de produção que processam componentes para uso nas linhas alimentadoras e para uso na linha principal. O Quadro 1 mostra a atribuição de tarefas para a linha principal e as linhas alimentadoras, e o Quadro 2 indica as atividades atribuídas às células de produção.

Para a Linha Alfa, foi escolhido o formato $U$, pois, nesse arranjo, os operários podem ser colocados no centro do layout, possibilitando o monitoramento e auxílio 
mútuos sempre que necessário (REKIEK; DELCHAMBRE, 2006). Neste sentido, como afirma Miltenburg (2001a), o espaço central da linha torna-se uma área de troca de informações e aprendizado mútuo. Miltenburg (2001b) mostra que nesse formato, o fluxo de produção e a movimentação dos operadores podem ser atribuídos tanto no sentido horário quanto no anti-horário. Para essa configuração, o autor lembra o fato de haver um constante estoque de Work in Process (WIP) entre as estações de trabalho, o que também permite a visualização de desbalanceamentos.

Também foi considerado que todas as atividades das estações de trabalho devem ser desenvolvidas sobre plataformas de montagem com dimensões capazes de comportar a área ocupada por um módulo da unidade habitacional, alcançando uma altura que permita o trabalho dos operários. Para isso, configurou-se as plataformas com 4.40 metros de largura por 5.20 metros de comprimento. A distância adotada entre estações de trabalho, levando em conta as dimensões das plataformas, foi de 5.80 metros, sendo essa medida suficiente para abrigar 1 plataforma que fica em espera para entrar na estação seguinte.

Quadro 1 - Estações de trabalho e tarefas atribuídas.

\begin{tabular}{|l|l|}
\hline Estação & Descrição das Atividades \\
\hline I - Linha Principal Alfa \\
\hline Alfa 1 & $\begin{array}{l}\text { Alinhamento e preparo da plataforma; Montagem da estrutura do contrapiso e } \\
\text { vedaça inferior }\end{array}$ \\
\hline Alfa 2 & Instalação de kits hidráulicos \\
\hline Alfa 3 & Colocação de isolamento e de placas de substrato \\
\hline Alfa 4 & Fixação de painéis internos \\
\hline Alfa 5 & Fixação de painéis externos \\
\hline Alfa 6 & Fixação de laje e cobertura \\
\hline Alfa 7 & Verificação da estrutura do LSF \\
\hline Alfa 8 & Colocação de isolamento, fixação de OSB e membrana \\
\hline Alfa 9 & Fixar siding vinílico \\
\hline Alfa 10 & $\begin{array}{l}\text { Fixação de OSB e PVC nos beirais e fixação das telhas shingle; Fixação de portas e } \\
\text { janleas }\end{array}$ \\
\hline Alfa 11 & Revestimento na laje; Revestimento de paredes internas \\
\hline Alfa 12 & Revestimento na laje; Revestimento de paredes internas \\
\hline Alfa 13 & Revestimentos pisos \\
\hline Alfa 14 & Fixação de louças, metais e chuveiro \\
\hline Alfa 15 & Acabamentos interno e externo; Verificações finais de acabamento \\
\hline
\end{tabular}


Quadro 1 - Continuação.

\begin{tabular}{|l|l|}
\hline Estação & Descrição das Atividades \\
\hline II - Linhas Alimentadoras Beta, Gama e Delta \\
\hline Beta 1 & Posicionar guias e montantes; parafusar ambos os lados \\
\hline Beta 2 & Passar eletrodutos; colocação de isolamento; fixação do gesso acartonado \\
\hline Beta 3 & Tratamento de juntas entre placas \\
\hline Gama 1 & Posicionar guias e montantes; parafusar ambos os lados \\
\hline Gama 2 & Passar eletrodutos; colocação de isolamento; fixação do gesso acartonado \\
\hline Gama 3 & Tratamento de juntas entre placas \\
\hline Delta 1 & Posicionar vigas e sanefas; parafusar ambos os lados \\
\hline Delta 2 & Passar eletrodutos; colocação de isolamento; fixação do gesso acartonado \\
\hline Delta 3 & Tratamento de juntas entre placas \\
\hline Delta 4 & Fixação da cobertura \\
\hline
\end{tabular}

Quadro 2 - Células de produção.

\begin{tabular}{|l|l|}
\hline Célula & Atividade \\
\hline C-2 & $\begin{array}{l}\text { Processamento de tubos de conexões hidráulicas para esgotamento sanitário: } \\
\text { montagem dos kits; }\end{array}$ \\
\hline C-8 & $\begin{array}{l}\text { Processamento das mantas de isolamento, cortes nas placas OSB e cortes nas } \\
\text { membranas hidrofugantes; }\end{array}$ \\
\hline C-9 & Cortes e adequações nas placas de siding vinílico; \\
\hline C-10 & $\begin{array}{l}\text { Processamento do PVC para forro dos beirais e cortes para adequação das telhas } \\
\text { shingle; }\end{array}$ \\
\hline C11 & Cortes no revestimento para a laje; Cortes no papel de parede e vinil; \\
\hline C-13 & Cortes no piso laminado e no vinil; \\
\hline C-15 & Cortes e adequações em mata-juntas; \\
\hline C- $\beta 2$ & $\begin{array}{l}\text { Cortes e adequações nas chapas de gesso acartonado, eletrodutos, caixas de } \\
\text { passagem e kits hidráulicos; }\end{array}$ \\
\hline C- $\gamma 2$ & $\begin{array}{l}\text { Cortes e adequações nas chapas de gesso acartonado, eletrodutos, caixas de } \\
\text { passagem e kits hidráulicos; }\end{array}$ \\
\hline C- 84 & Montagem de tesouras, fixação de OSB nas tesouras. \\
\hline
\end{tabular}

Com relação ao fluxo das linhas, para fins de simulação, sugeriu-se a adoção do sistema chamado cart-on-track por não exigir altos níveis de automação e por permitir que o próprio operário controle a movimentação. Tompkins e White (1984) mostram que o mecanismo desse sistema baseia o percurso e a plataforma em um 
tubo rotativo. O funcionamento é relativamente simples e pode ser descrito da seguinte forma, conforme Aized (2010): a plataforma é engatada nos trilhos sendo movimentada pelo tubo rotativo, no qual está conectada uma roda de acionamento que pode ser rotacionada em ângulos que variam de 0 até 45o; assim, variando-se o ângulo, obtêm-se velocidades diferentes. A Figura 2 ilustra esse sistema. Dessa forma Tompkins e White (1984) mostram que as plataformas podem ser controladas de maneira independente, permitindo a alocação de várias plataformas no percurso. Isso é possível porque as plataformas podem ficar paradas quando a roda de acionamento estiver paralela ao tubo rotativo.

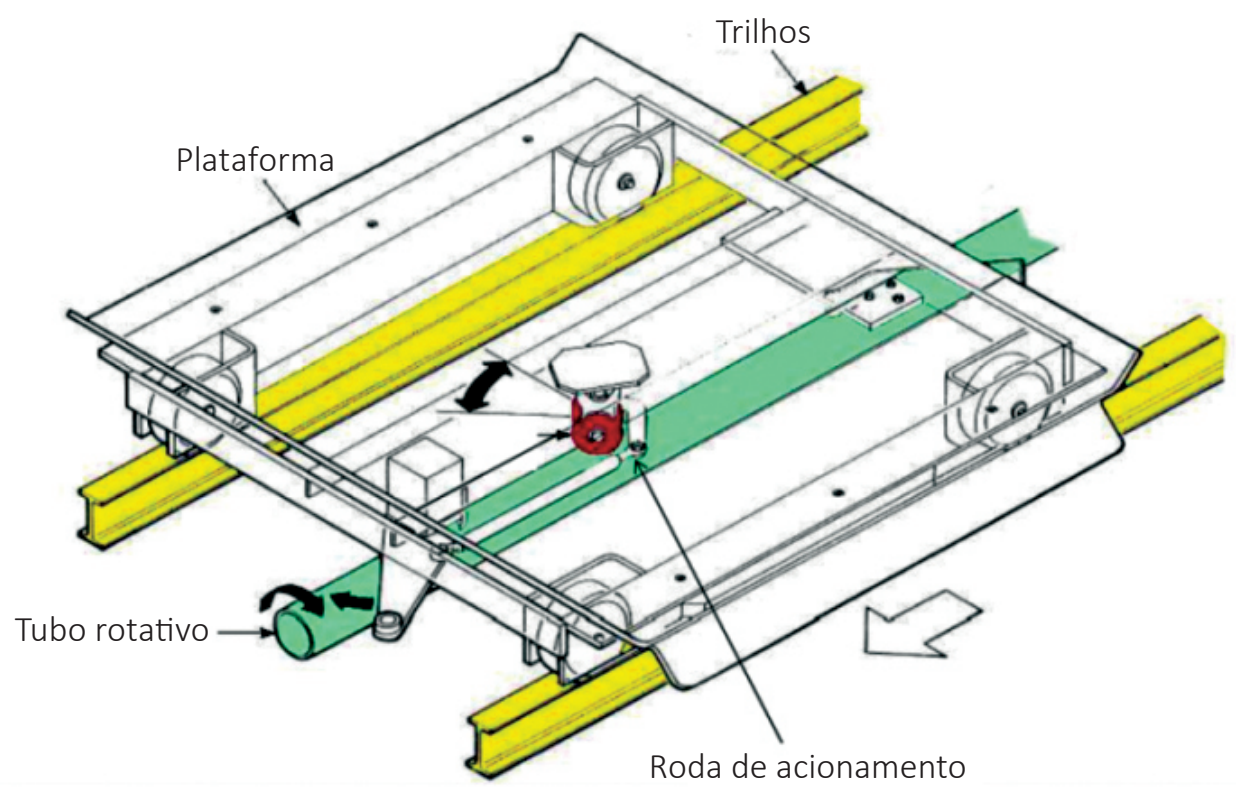

Figura 2 - Sistema cart-on-track. Fonte: Adaptado de Aized, 2010.

Ao longo das linhas, há alguns pontos em que existe a necessidade de mudança de direção das plataformas em função do layout do sistema e em função do retorno das plataformas. Nesse caso, foram considerados pontos de mudança aqueles em que os trilhos são rotacionados, a fim de que se alinhem em direção ao novo percurso. Esse mecanismo, conhecido como round track, é estruturado nos próprios trilhos das linhas de montagem e permitem as mudanças de direção necessárias quando não é possível ou viável o uso de esteiras. Assim, na Figura 3, é mostrado o layout do sistema proposto, com as orientações de fluxo e demais considerações necessárias para o funcionamento. 


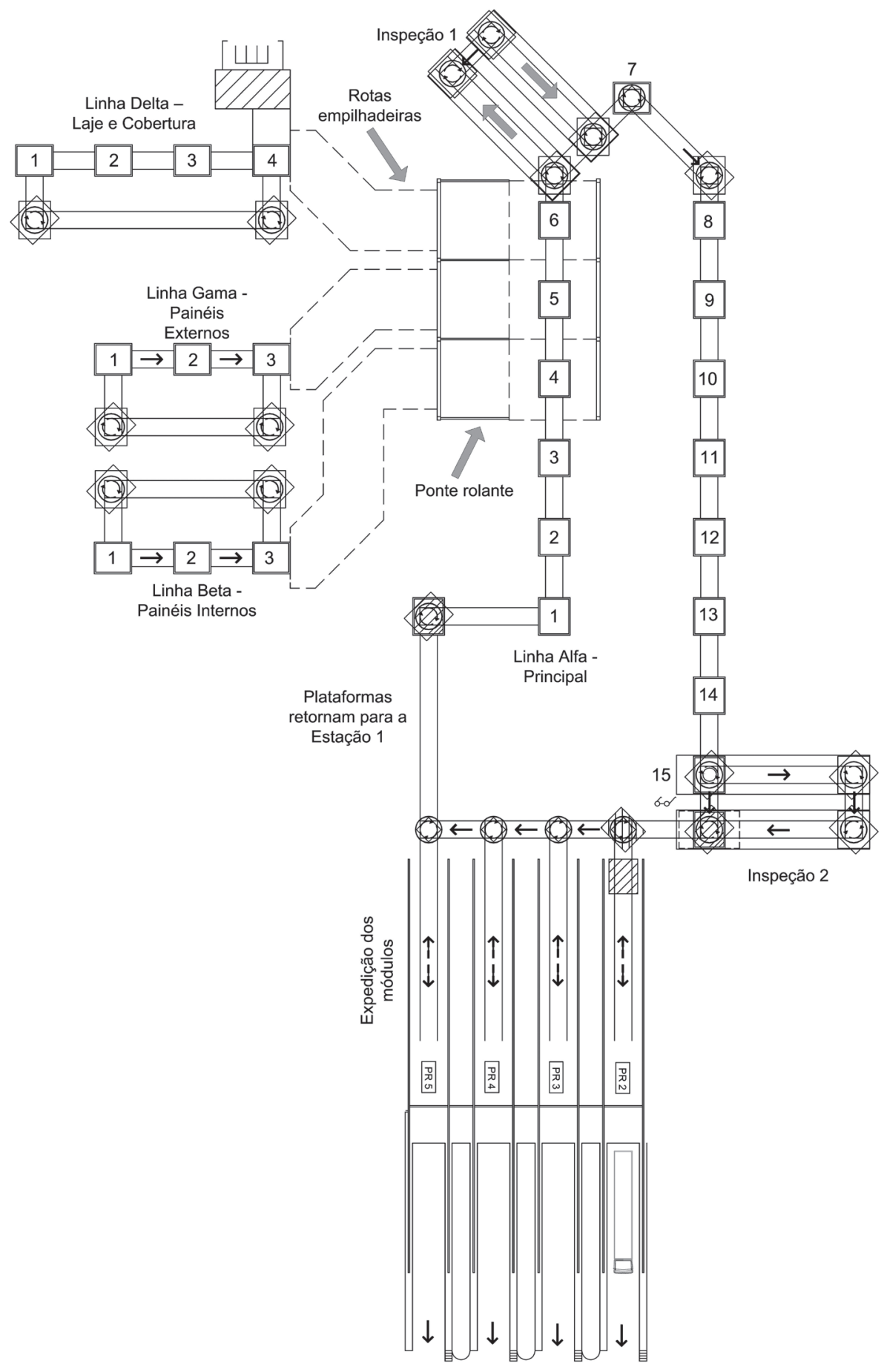

Figura 3 - Sistema de produção. 
Cada estação de trabalho desempenha atividades para o processamento de diferentes elementos e/ou componentes. Portanto, os tempos de processamento de cada estação variam de acordo com a sua finalidade, as ferramentas e/ou máquinas que estão sendo utilizadas e com a quantidade de operários que desempenham essas atividades. Os tempos de cada tarefa foram calculados com base em índices de produtividade da construção para o sistema LSF e na coleta de dados em obras residenciais que utilizaram tal sistema construtivo. Cabe destacar que algumas condições foram pré-estabelecidas para o cálculo dos tempos, sendo elas:

- Todas as atividades obedecem à sequência de montagem, determinada pelo projeto da montagem de cada elemento do módulo;

- Para cada estação, os movimentos são desempenhados por um montador e um ajudante;

- Nos locais onde há supermercados de componentes ou elementos grandes, montador e ajudante deslocam-se para carregar e transportar tais peças, impactando no valor final do tempo;

- Nos locais onde há supermercados de componentes pequenos, apenas o ajudante desloca-se para carregar e transportar, não impactando no valor final do tempo;

- Todas as peças e componentes nos supermercados estão dispostas no chão, exigindo que os operários se abaixem para carregar;

- As atividades de parafusamento são todas realizadas com parafusadeira elétrica ao alcance dos operários.

Assim, para a linha principal, os tempos de processamento dos módulos em cada estação de trabalho estão atribuídos na Tabela 1, bem como as equipes alocadas.

Tabela 1 - Tempos de processamento na linha principal e equipes alocadas.

\begin{tabular}{llllll}
\hline Estação & $\begin{array}{l}\text { Equipe } \\
\text { (operários) }\end{array}$ & $\begin{array}{l}\text { Módulo 1 } \\
(\mathrm{min})\end{array}$ & $\begin{array}{l}\text { Módulo 2 } \\
(\mathrm{min})\end{array}$ & $\begin{array}{l}\text { Módulo 3 } \\
(\mathrm{min})\end{array}$ & $\begin{array}{l}\text { Módulo 4 } \\
(\mathrm{min})\end{array}$ \\
\hline Alfa 1 & 2 & 33.0 & 33.0 & 33.0 & 33.0 \\
\hline Alfa 2 & 2 & 0 & 0 & 0 & 22.0 \\
\hline Alfa 3 & 2 & 26.0 & 26.0 & 26.0 & 26.0 \\
\hline Alfa 4 & 2 & 7.0 & 7.0 & 7.0 & 12.0 \\
\hline Alfa 5 & 2 & 7.0 & 7.0 & 7.0 & 7.5 \\
\hline Alfa 6 & 2 & 12.0 & 12.0 & 12.0 & 12.0 \\
\hline
\end{tabular}


Tabela 1 - Continuação.

\begin{tabular}{llllll}
\hline Estação & $\begin{array}{l}\text { Equipe } \\
\text { (operários) }\end{array}$ & $\begin{array}{l}\text { Módulo 1 } \\
(\mathrm{min})\end{array}$ & $\begin{array}{l}\text { Módulo 2 } \\
(\mathrm{min})\end{array}$ & $\begin{array}{l}\text { Módulo 3 } \\
(\mathrm{min})\end{array}$ & $\begin{array}{l}\text { Módulo 4 } \\
(\mathrm{min})\end{array}$ \\
\hline Inspeção & 1 & 5.0 & 5.0 & 5.0 & 5.0 \\
\hline Alfa 7 & 2 & 18.5 & 18.5 & 18.5 & 25.0 \\
\hline Alfa 8 & 4 & 21.5 & 21.5 & 21.5 & 21.5 \\
\hline Alfa 9 & 4 & 31.5 & 31.5 & 31.5 & 31.5 \\
\hline Alfa 10 & 4 & 30.4 & 30.4 & 30.4 & 30.4 \\
\hline Alfa 11 & 6 & 20.65 & 20.65 & 20.65 & 24.25 \\
\hline Alfa 12 & 6 & 20.65 & 20.65 & 20.65 & 24.25 \\
\hline Alfa 13 & 2 & 35.0 & 35.0 & 35.0 & 35.0 \\
\hline Alfa 14 & 2 & 0 & 0 & 0 & 30.0 \\
\hline Alfa 15 & 5 & 35.0 & 35.0 & 35.0 & 40.0 \\
Inspeção final & & & & & \\
\hline
\end{tabular}

Para as linhas alimentadoras, os tempos de processamento dos elementos podem ser visualizados na Tabela 2. Todas as estações das linhas alimentadoras possuem 2 operários alocados.

Tabela 2 - Tempos de processamento nas linhas alimentadoras.

\begin{tabular}{lllll}
\hline Elemento & \multicolumn{4}{l}{ Estações e tempos associados (minutos) } \\
\hline Painel interno 3 & $\beta 1(3.2)$ & $\beta 2(12.9)$ & $\beta 3(12.9)$ & - \\
\hline Painel interno 14 & $\beta 1(7.4)$ & $\beta 2(15.3)$ & $\beta 3(15.3)$ & - \\
\hline Painel externo 1 & $\gamma 1(4.6)$ & $\gamma 2(12.9)$ & $\gamma 3(12.9)$ & - \\
\hline Painel externo 10 & $\gamma 1(7.8)$ & $\gamma 2(15.3)$ & $\gamma 3(15.3)$ & - \\
\hline Laje e cobertura 1 & $\delta 1(12.4)$ & $\delta 2(17.0)$ & $\delta 3(17.0)$ & $\delta 4(24.8)$ \\
\hline Painel interno 4 & $\beta 1(5.7)$ & $\beta 2(12.9)$ & $\beta 3(12.9)$ & - \\
\hline Painel interno 15 & $\beta 1(8.2)$ & $\beta 2(15.3)$ & $\beta 3(15.3)$ & - \\
\hline Painel externo 2 & $\gamma 1(4.6)$ & $\gamma 2(12.9)$ & $\gamma 3(12.9)$ & - \\
\hline Painel externo 11 & $\gamma 1(9.0)$ & $\gamma 2(15.3)$ & $\gamma 3(15.3)$ & - \\
\hline Laje e cobertura 2 & $\delta 1(12.4)$ & $\delta 2(17.0)$ & $\delta 3(17.0)$ & $\delta 4(24.8)$ \\
\hline Painel interno 8 & $\beta 1(3.2)$ & $\beta 2(12.9)$ & $\beta 3(12.9)$ & - \\
\hline Painel interno 16 & $\beta 1(7.4)$ & $\beta 2(15.3)$ & $\beta 3(15.3)$ & - \\
\hline
\end{tabular}


Tabela 2 - Continuação.

\begin{tabular}{lllll}
\hline Elemento & \multicolumn{4}{l}{ Estações e tempos associados (minutos) } \\
\hline Painel externo 5 & $\gamma$ 1 (4.6) & $\gamma$ 2 (12.9) & $\gamma 3(12.9)$ & - \\
\hline Painel externo 12 & $\gamma 1(7.8)$ & $\gamma 2(15.3)$ & $\gamma 3(15.3)$ & - \\
\hline Laje e cobertura 3 & $\delta 1(12.4)$ & $\delta 2(17.0)$ & $\delta 3(17.0)$ & $\delta 4(24.8)$ \\
\hline Painel interno 6 & $\beta 1(5.7)$ & $\beta 2(12.9)$ & $\beta 3(12.9)$ & - \\
\hline Painel interno 17 & $\beta 1(7.4)$ & $\beta 2(15.3)$ & $\beta 3(15.3)$ & - \\
\hline Painel interno 19 & $\beta 1(5.7)$ & $\beta 2(12.9)$ & $\beta 3(12.9)$ & - \\
\hline Painel externo 9 & $\gamma 1(4.6)$ & $\gamma 2(12.9)$ & $\gamma 3(12.9)$ & - \\
\hline Painel externo 13 & $\gamma 1(6.1)$ & $\gamma 2(10.4)$ & $\gamma 3(10.4)$ & - \\
\hline Painel externo 18 & $\gamma$ 1 (2.7) & $\gamma 2(4.55)$ & $\gamma 3(4.55)$ & - \\
\hline Painel externo 20 & $\gamma$ 1 (1.5) & $\gamma 2(4.15)$ & $\gamma 3(4.15)$ & - \\
\hline Laje e cobertura 4 & $\delta 1(12.4)$ & $\delta 2(17.0)$ & $\delta 3(17.0)$ & $\delta 4(24.8)$ \\
\hline
\end{tabular}

\subsection{Simulação Computacional}

Assim, com as variáveis do modelo devidamente configuradas, foi iniciada a simulação computacional. A seguir, são apresentados os resultados dessa simulação com os resultados dos tempos de ciclo médios, lead time médio e níveis máximos de trabalho em progresso, organizados na Tabela 3.

Tabela 3 - Tempos de ciclo dos módulos e da unidade habitacional.

\begin{tabular}{llll}
\hline Produto & Tempo de ciclo médio & Lead time médio & WIP máximo \\
\hline Módulo 1 & $242.27 \mathrm{~min}$ & $121.59 \mathrm{~min}$ & 7 \\
\hline Módulo 2 & $242.36 \mathrm{~min}$ & $121.68 \mathrm{~min}$ & 7 \\
\hline Módulo 3 & $242.46 \mathrm{~min}$ & $121.79 \mathrm{~min}$ & 7 \\
\hline Módulo 4 & $242.65 \mathrm{~min}$ & $122.00 \mathrm{~min}$ & 7 \\
\hline Unidade habitacional & $242.65 \mathrm{~min}$ & $487.06 \mathrm{~min}$ & - \\
\hline
\end{tabular}

Analisando os resultados da Tabela 3 nota-se que o tempo de ciclo da unidade habitacional é de $242.65 \mathrm{~min}$. e o lead time médio é de $487.06 \mathrm{~min}$., que em horas representa, respectivamente, 4.04 horas e 8.12 horas, ou seja, uma unidade habitacional completa leva pouco mais de 8 horas para ficar pronta, sendo o sistema capaz de entregar uma unidade a cada 4 horas. Já o WIP teve um valor registrado de 7 unidades para cada módulo, o qual é controlado pelo sistema Just-in-Time programado 
no modelo simulado. No que diz respeito ao desempenho das estações de trabalho, na Tabela 4 estão as porcentagens relativas ao comportamento das estações da linha principal e das linhas alimentadoras.

Tabela 4 - Estado das estações de trabalho.

\begin{tabular}{lllll}
\hline Estações & \% Operação & \% Ociosa & \% Espera & \% Bloqueada \\
\hline Alfa 1 & 56,57 & 2,07 & & 41,36 \\
\hline Alfa 2 & 8,49 & 2,05 & & 89,46 \\
\hline Alfa 3 & 45,02 & 1,28 & & 53,69 \\
\hline Alfa 4 & 14,18 & 1,17 & 31,05 & 53,6 \\
\hline Alfa 5 & 12,15 & 1,18 & 28,08 & 58,6 \\
\hline Alfa 6 & 20,46 & 1,12 & 12,41 & 66,01 \\
\hline Alfa 7 & 35,09 & 0,92 & & 64 \\
\hline Alfa 8 & 36,96 & 0,69 & & 62,35 \\
\hline Alfa 9 & 52,71 & 0,54 & & 46,74 \\
\hline Alfa 10 & 99,59 & 0,41 & & \\
\hline Alfa 11 & 68,53 & 31,47 & & \\
\hline Alfa 12 & 68,6 & 31,4 & & \\
\hline Alfa 13 & 56,87 & 43,13 & & 0,15 \\
\hline Alfa 14 & 13,03 & 86,82 & & 56,35 \\
\hline Alfa 15 & 61,74 & 38,19 & 0,07 & 59,19 \\
\hline MÉDIA & 43,33 & 16,16 & 7,96 & 59,08 \\
\hline Beta 1 & 23,56 & 8,19 & & 38,24 \\
\hline Beta 2 & 55,6 & 5,63 & & 38,77 \\
\hline Beta 3 & 55,34 & 6,66 & & 38,71 \\
\hline MÉDIA & 44,83 & 6,83 & 0,00 & \\
\hline Gama 1 & 22,19 & 6,51 & & 48,34 \\
\hline Gama 2 & 48,02 & 5,82 & & \\
\hline Gama 3 & 48,19 & 6,12 & & \\
\hline MÉDIA & 39,47 & 6,15 & & \\
\hline Delta 1 & 21,25 & 12,4 & & \\
\hline Delta 2 & 28,93 & 11,88 & \\
\hline Delta 3 & 29,11 & 11,81 & & \\
\hline Delta 4 & 42,07 & 11,71 & & \\
\hline Média & 30,34 & 11,95 & & \\
\hline & & & & \\
\hline
\end{tabular}


Pela Tabela 4, nota-se que as estações de trabalho passam grande parte do tempo ocupadas, desempenhando as tarefas necessárias para a conclusão dos produtos. Com os resultados apresentados, pode-se calcular a eficiência do sistema de produção. O cálculo da eficiência da linha pode ser feito pelo uso da Equação 1:

$$
E=\frac{W C}{M \times C}
$$

O uso dessa equação depende, portanto, do conteúdo de trabalho (WC), número de estações de trabalho (M) e tempo de ciclo (C). De acordo com a soma dos valores dos tempos de processamento médios para os quatro módulos, o WC é identificado pelo valor de 1.550,40 min. Já o valor de M é de 15 estações de trabalho (tendo em vista que as alimentadoras não participam diretamente do processamento dos módulos, atuando apenas como fornecedoras de componentes), e o tempo de ciclo (C) é de 242.65 min. Assim, a eficiência do sistema é de (Equação 2):

$$
E=\frac{1550.40}{15 \times 242.65}=0.4259=42.59 \%
$$

Os resultados dessa simulação mostram que é possível entregar habitações de qualidade em poucas horas, sendo necessário, para isso, a promoção da inovação tecnológica como atributo essencial. O sistema proposto foi capaz de entregar uma casa a cada 4 horas, quantidade que, em termos de índices correntes na construção civil, representa algo muito difícil de ser obtido, tendo em vista as atuais condições de produção.

Além disso, os desperdícios, quando comparados ao de sistemas tradicionais de construção, são drasticamente reduzidos. Por ser um sistema fabril, o desperdício de materiais é menor e possui um nível de controle mais favorável do que num canteiro de obras, por exemplo. Destaca-se que, em termos de desperdício, o sistema proposto apresenta uma de suas maiores vantagens em face dos métodos tradicionais, tendo em vista que as denominadas atividades de fluxo são reduzidas e controladas de acordo com a demanda do sistema.

\section{Conclusões}

A contribuição dos resultados deste estudo, tanto no âmbito acadêmico quanto prático, pode ser identificada em dois pontos principais. O primeiro deles é a definição de um layout de produção específico para unidades habitacionais em LSF, fato pouco explorado na literatura e com resultados inexpressivos sob o ponto de vista do conceito de linhas de montagem. O segundo refere-se ao resultado da simulação computacional, que permitiu o estudo do comportamento do sistema de produção e, 
consequentemente, a compreensão da relação de causa e efeito entre as variáveis dos modelos, garantindo a sintonia entre os elementos do sistema.

Considera-se que os resultados apresentados são de importância para o avanço da construção civil. O desenvolvimento do layout e os resultados apresentados pelas simulações mostram que é perfeitamente possível implementar meios de produção mais eficazes e que não fazem parte da rotina da construção na maioria dos países. Associado a isso, o sistema construtivo LSF corrobora para o aumento da qualidade das edificações, tendo em vista as características de industrialização de seus componentes. Além disso, os ciclos de produção obtidos (pouco mais de 4 horas) representam um prazo de entrega incomum nas atuais condições da construção civil brasileira. A rapidez de entrega e montagem das casas mostram que é possível entregar habitações com qualidade em pouco tempo e com baixa utilização de recursos, em termos comparativos com os tradicionais canteiros de obras.

Nesse sentido, é necessário destacar a contribuição deste estudo para a redução do déficit habitacional no país. A rapidez de entrega das casas, associado à qualidade que o sistema LSF pode garantir, além do baixo uso de recursos, mostram que as políticas adotadas pelo poder público são, geralmente, ineficazes, pois não contemplam a inovação tecnológica na construção. Pelo contrário, incentivam o uso das velhas técnicas de construção. Como demonstrado, seria possível reduzir o déficit habitacional apenas com algumas mudanças que garantem tanto melhores condições de trabalho para os operários quanto melhores níveis de qualidade para as casas que são entregues.

Outro ponto de relevância a ser destacado diz respeito à flexibilidade do sistema de produção proposto. Apesar das simulações terem sido executadas para a montagem de módulos que formam uma unidade habitacional, o sistema de produção também poderia ser utilizado apenas para a montagem de painéis, por exemplo, o que resultaria em tempos de ciclo mais baixos ainda. Outra opção seria a mudança do sistema construtivo. Tendo em vista que o sistema de produção é essencialmente manual, o LSF pode ser substituído pelo Wood Frame, sem grandes adaptações, uma vez que os dois sistemas são semelhantes.

Ainda com relação à flexibilidade do sistema, outro ponto a ser destacado diz respeito aos modelos que podem ser montados. A princípio, qualquer modelo pode ser entregue pelo sistema de produção, desde que as questões relativas à modulação e requisitos do sistema construtivo sejam obedecidas. Nesse sentido, é possível entregar uma grande variedade de modelos que podem abranger diferentes tipos de mercado, levando-se em conta que cada modelo implica em tempos de ciclo e lead time diferentes.

Finalmente, o desempenho do modelo pode ser encarado como realístico, tendo em vista que os tempos de processamento foram obtidos a partir de medições 
em obras e da análise da literatura, associado ao fato de terem sido atribuídas variações a tais tempos. Além disso, os tempos atribuídos nas estações de trabalho podem ser efetivamente reduzidos, dado que o fator de aprendizagem e a experiência das equipes influenciam diretamente no comportamento das estações. Assim, a variação dos tempos programada nos modelos pode ser significativamente reduzida, e os tempos padrão de processamento podem, também, ser reduzidos, mesmo não havendo automação das atividades.

\section{Referências}

AIZED, T. In: Future Manufacturing Systems. Tauseef Aized (Ed.). p. 121-137. Intech. 2010. BACHEGA, S.J. Simulação de sistemas de coordenação de ordens em ambiente de produção flow shop. Tese. Programa de Pós-Graduação em Engenharia de Produção. UFSCar. São Carlos. 2013.

BAUTISTA, J.; PEREIRA, J. Ant algorithms for a time and space constrained assembly line balancing problem. European Journal of Operational Research. 177. p. 2016-2032. 2007.

BERTELSEN, S.; HENRICH, G.; KOSKELA, L.; ROOKE, J. Construction physics. Proceedings of the 15th Annual Conference of the International Group for Lean Construction. 2008.

GOMES, M.L.B. Um modelo de nivelamento da produção à demanda para a indústria de confecções do vestuário segundo os novos paradigmas da melhoria de fluxos de processos. Tese (Doutorado em Engenharia de Produção) - Programa de Pós-Graduação em Engenharia de Produção - Universidade Federal de Santa Catarina. Florianópolis - SC, 2002.

HAMMAD, A.A. Simulation modeling for manufactured housing processes. Master's Thesis, University of Cincinnati, Cincinnati, OH. 2002.

KOSKELA, L. An exploration towards a production theory and its application to construction. VTT Technical Research Centre of Finland. 2000.

KOSKELA, L. Application of the new production philosophy to construction.Stanford, EUA, CIFE, Technical Report, n. 72. 1992.

KOSKELA, L. Lean construction as a movement towards theory-based construction management. Salford Centre for Research and Innovation (SCRI). International Symposium, Salford, UK. 2004.

KOSKELA, L.; VRIJHOEF, R. Is the current theory of construction a hindrance to innovation? Building Research and Information, v. 29. 2001.

LANE, G. Made-to-order Lean: Excelling in a High-mix, Low-volume Environment. Productivity Press, 2007.

LEE, A.; ENGLIN, J. Using a model and empirical data to analyze manufactured home conservation retrofits. Energy and Buildings, v. 13, n. 1, p. 73-83, 1989. 
MEHROTRA, N.; SYAL, M.; HASTAK, M. Manufactured housing production process and layout design. Bridges, v. 10, n. 40671, p. 43, 2003.

MEHROTRA, M.; SYAL, M.; HASTAK, M. Manufactured housing production layout design. Journal of Architectural Engineering, v. 11, n.1, p.25-34. 2005.

MILTENBURG, J. One-piece flow manufacturing on U-shaped production lines: a tutorial. IIE Transactions, v. 33, n. 4, pp. 303-321. 2001b.

MILTENBURG, J. U-shaped production lines: a review of theory and practice. International Journal of Production Economics, v. 70, n. 3, p. 201-214. 2001 a.

REKIEK, B.; DELCHAMBRE, A. Assembly line design: the balancing of mixed-model hybrid assembly lines with genetic algorithms. Springer Series in Advanced Manufacturing. UK. 2006.

TOMPKINS, J.A.; WHITE, J.A. Facilities planning. New York: John Wiley, 1984.

TUBINO, D.F. Sistemas de produção no chão de fábrica. Porto Alegre: Bookman, 1999. 


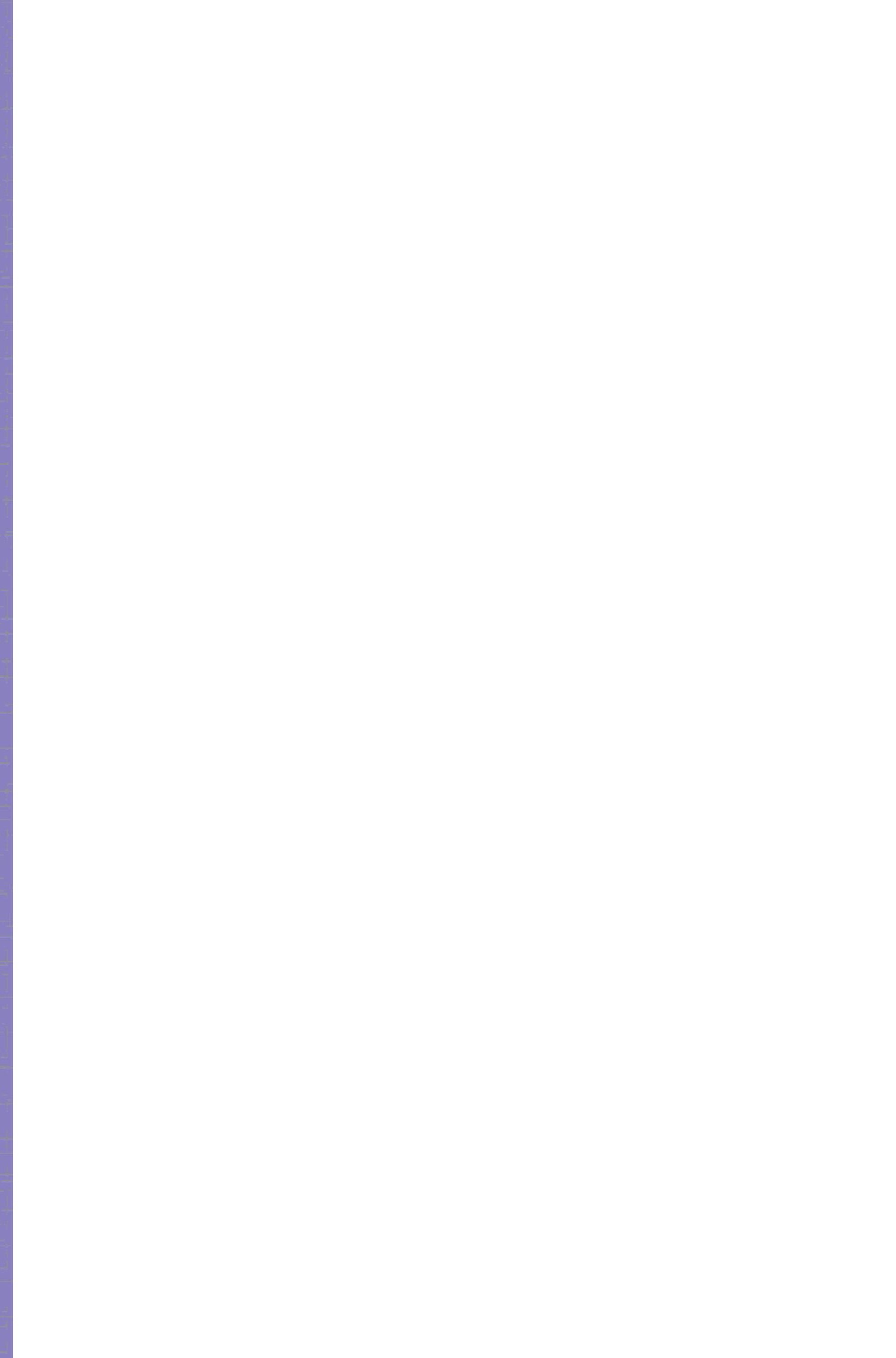

